OPEN ACCESS

Edited by:

Hanting Zhang,

West Virginia University, USA

Reviewed by:

William Griffith,

Texas A\&M University Baylor College of Dentistry, USA

Neha Sehgal,

Wisconsin Institute for Discovery, USA

*Correspondence:

Saloua Benmansour benmansour@uthscsa.edu

Received: 11 August 2016 Accepted: 06 December 2016 Published: 21 December 2016

Citation:

Benmansour S, Arroyo LD and Frazer A (2016) Comparison of the

Antidepressant-Like Effects

of Estradiol and That of Selective Serotonin Reuptake Inhibitors in Middle-Aged Ovariectomized Rats.

Front. Aging Neurosci. 8:311. doi: 10.3389/fnagi.2016.00311

\section{Comparison of the} Antidepressant-Like Effects of Estradiol and That of Selective Serotonin Reuptake Inhibitors in Middle-Aged Ovariectomized Rats

\author{
Saloua Benmansour ${ }^{1 *}$, Luis D. Arroyo ${ }^{1}$ and Alan Frazer ${ }^{1,2}$ \\ ${ }^{1}$ Department of Pharmacology, University of Texas Health Science Center at San Antonio, San Antonio, TX, USA, ${ }^{2}$ South \\ Texas Veterans Health Care System, San Antonio, TX, USA
}

This study investigated the effect of age and that of the post-ovariectomy (OVX) time interval on the antidepressant (AD)-like effects of estradiol $\left(E_{2}\right)$ and selective serotonin reuptake inhibitors (SSRIs) in middle-aged (10 month) OVX rats (10m-OVX). Acute or chronic effects of these treatments in 10m-OVX were compared with those (1) in young adult (4-month) OVX rats (4m-OVX) or with older (14-month) OVX rats (14m-OVX), at a short time: 2 weeks post-OVX (+2w) and (2) in 10m-OVX rats after a longer times: 4 or 8 months post-OVX $(+4 \mathrm{~m}$ or $+8 \mathrm{~m})$. Using in vivo chronoamperometry in the CA3 region of the hippocampus, $E_{2}$ at 20 pmol, a dose shown previously to inhibit the serotonin transporter (SERT) in 4m-OVX, had no effect in $10 \mathrm{~m}-\mathrm{OVX}+2 \mathrm{w}$. A higher dose of $\mathrm{E}_{2}$ (40 pmol) increased T80 value, a measure of serotonin or 5-hydroxytryptamine (5-HT) clearance, and also blocked the ability of fluvoxamine to increase T80. By contrast, estradiol had no effects on SERT function in $10 \mathrm{~m}-\mathrm{OVX}+4 \mathrm{~m}$, even at a higher dose than 40 pmol. Fluvoxamine slowed $5-\mathrm{HT}$ clearance in $10 \mathrm{~m}-\mathrm{OVX}$ at $+2 \mathrm{w},+4 \mathrm{~m}$ and $+8 \mathrm{~m}$ post-OVX as it did in the 4m-OVX. Using the forced swim test, 2 weeks treatment with $\mathrm{E}_{2}$ (5 $\mathrm{\mu g} /$ day), a dose shown previously to induce AD-like effects in $4 \mathrm{~m}-\mathrm{OVX}$, had no effect in 10m-OVX+2w. However, a higher dose (10 $\mu \mathrm{g} /$ day) of $E_{2}$ induced an AD-like effect as demonstrated by significantly increased swimming behavior and decreased immobility. This effect was not seen in $10 \mathrm{~m}-\mathrm{OVX}+4 \mathrm{~m}$. By contrast, significant AD-like effects were obtained in $14 \mathrm{~m}-\mathrm{OVX}+2 \mathrm{w}$, thereby demonstrating that the lack of an $A D$ effect of $E_{2}$ is due to the 4-month hormone withdrawal and not to an age effect. After 2 weeks treatment with the SSRI sertraline, similar AD-like effects were obtained in $10 \mathrm{~m}-\mathrm{OVX}$ tested at $+2 \mathrm{w},+4 \mathrm{~m}$ or $+8 \mathrm{~m}$ post-OVX as those found in $4 \mathrm{~m}-\mathrm{OVX}$. Thus, the potency of estradiol to produce effects consistent with inhibition of the SERT was not only decreased in older rats but its effects were markedly diminished the longer hormonal depletion occurred. By contrast, the ability of SSRIs to inhibit the SERT was not affected either by age or the length of hormonal depletion.

Keywords: middle age, OVX rats, estradiol, SSRI, FST, SERT function, critical period 


\section{INTRODUCTION}

The efficacy of antidepressants (ADs) in the elderly suffering from major depressive disorder (MDD) is controversial (Kasper et al., 2005; Nelson et al., 2008). Although tricyclic ADs and selective serotonin reuptake inhibitors (SSRIs) are reported to be effective in clinical trials with older patients (Gareri et al., 2000; Salzman et al., 2002; Blazer, 2003) some authors have claimed that their effectiveness is reduced compared to that found in young adults (Lenze et al., 2008; Sheffrin et al., 2009; Tedeschini et al., 2011). Moreover, it has been suggested that such decline begins at middle age as a modest reduction that becomes more pronounced at senescence (Tedeschini et al., 2011).

MDD occurs about twice as frequently in women as in men (Kupfer et al., 2012), with increased occurrence in middle age, around the menopausal transition (Maartens et al., 2002). In fact, the onset or exacerbation of depressive symptoms has been associated with the time around perimenopause (Maki et al., 2010; Soares, 2013). This has provided a rationale to try either estrogen replacement therapy (ERT) or hormone replacement therapy (HRT) in such patients. Such treatment has been reported to have AD effects in peri- and postmenopausal women (Frey et al., 2008; Soares and Frey, 2010), although this is not a universal finding (Morrison et al., 2004). ADs are also used to treat depression in menopausal women. Some reports indicate that the $\mathrm{AD}$ response could be modified not only by aging but also the endocrine condition. Although some find pre-menopausal women are more responsive than post-menopausal women to ADs (Soares et al., 2001; Huang et al., 2008; Pae et al., 2009), this is not a universal finding (Kornstein et al., 2013, 2015). A combination of estrogen and $\mathrm{AD}$ is also often used to treat depression in menopausal women. However, there appears to be little evidence that taking SSRIs in conjunction with ERT produces greater improvement in depressive symptoms than that seen with an SSRI alone (Frey et al., 2008).

A possible reason for such discrepancy in results is the time when $\mathrm{AD}$ treatment was started in relation to menopause onset. A "window of opportunity" or "the critical period" hypothesis has been postulated for the effects of estrogen (Rocca et al., 2011), which proposes that ERT is only beneficial if administration is begun during a time window in close proximity to menopause (Resnick and Henderson, 2002). Many studies have examined the critical period hypothesis for estradiol's effects with respect to cognition but only a few clinical studies have investigated the effect of the time of initiation of ERT and/or AD therapy after menopause in mood disorders (Craig, 2013). It has been suggested that menopausal status and old age are predictors of a poor response to AD treatment (Pae et al., 2009).

The aims of the present study were to explore whether the age (4-month, 10-month, and 14-month OVX rats) and/or postOVX interval ( 2 weeks versus 4 months or 8 months) influences the AD effect of estradiol and that of SSRIs in middle-aged 10month OVX rats. Many studies primarily examined the acute effects of estradiol or ADs in middle-aged rats; however, such treatments are given chronically to post-menopausal depressed patients. Therefore, this study examined not only the acute effects of $E_{2}$ and of SSRI, using chronoamperometry to provide a direct measure of the effect of local application of an SSRI into the CA3 region of the hippocampus on serotonin transporter (SERT) function, but also the behavioral consequences of chronic treatments with estradiol and with SSRIs in the forced swim test (FST). The FST provides a behaviorally relevant but more indirect measure of the effect of the treatments on SERT function (Cryan et al., 2002). Chronoamperometry experiments, as stated above, are carried out in the CA3 region of hippocampus. This specific area of hippocampus was selected based on earlier work showing that under our experimental conditions active clearance of exogenous 5-hydroxytryptamine (5-HT) from it was due exclusively to the SERT (Daws et al., 1998). The hippocampus, in general, is an appropriate area to study AD effects on SERT function and the influence of ovarian steroids on such effects. It receives a dense serotonergic innervation, with perhaps some preferential innervation from the median raphe (Jacobs and Azmitia, 1992). There is an abundance of data indicating that the SERT is the key, initial cellular target for SSRIs (Lenox and Frazer, 2002). Also, estrogen is known to affect the anatomy and physiology of the rodent hippocampus (McEwen and Alves, 1999). There are substantial estrogen receptor (ER) $\alpha$ and ER $\beta$ protein in the hippocampus in general and in CA3 in particular (Shughrue and Merchenthaler, 2000). In addition, both the anatomy and function of the hippocampus are affected by $\mathrm{AD}$ treatment (Castrén and Rantamäki, 2010; Duman and Li, 2012).

\section{MATERIALS AND METHODS}

\section{Animals}

Ovariectomized (OVX) rats (Sprague-Dawley; 4-month, 10month, and 14-month-old, Envigo, Indianapolis, IN, USA) were housed on a $12 \mathrm{~h}: 12 \mathrm{~h}$ light/dark cycle with lights on at 07:00 and with food and water provided ad libitum. All animal procedures were in accordance with the National Institutes of Health Guide for the Care and Use of Laboratory Animals and were approved by the local Institutional Animal Care and Use Committee. All efforts were made to minimize the number of animals used, or stress and discomfort to the animals during the experimental procedure. In general, OVX rats (4-month, 10-month, and 14month) were used 2 weeks after ovariectomy (to allow recovery after surgery before the start of the experiment). However, in studies investigating the effect of time post-OVX, 10-month-old OVX rats were also used 4 months or 8 months post-ovariectomy.

\section{Choice of Animal Model}

The incidence of regular estrous cyclicity decreases progressively during aging. Between 8 and 12 months of age, female SpragueDawley rats display prolonged irregular cycles (Matt et al., 1986), a period named periestropause or recurrent pseudopregnancy and is characterized by high levels of follicle-stimulating hormone (FSH) and luteinizing hormone (LH) in comparison with those in young female rats in diestrus (Bestetti et al., 1991). This stage is analogous to perimenopause or menopause transition in women where menstrual cycle irregularities are related to increased levels in FSH and LH (Prior, 1998). The state of complete loss of reproductive capacity in rodents, 
called estropause, is characterized by persistent diestrus. Lower levels of estradiol (Bestetti et al., 1991) as well as higher levels (Wise and Ratner, 1980; Gore et al., 2000) were reported in middle-aged rats in persistent diestrus as compared with young females in the same estrous-cycle phase. These differences seem to depend upon the strain of rat, age and sensitivity of the hormone assay. Rat estropause differs from monkey and human menopause in that aged rats retain a much larger number of primary oocytes, resulting in higher estrogen levels at the onset of persistent diestrus than those seen in primates after menopause (Chakraborty and Gore, 2004). To limit this difference, in this study rats entering estropause (10-monthold) were ovariectomized thus providing a model that mimics better both the age and ovarian hormone status of peri- and postmenopausal women.

\section{Choice of SSRIs Used in Acute and Chronic Studies}

For the acute studies, the SSRI fluvoxamine was used in the in vivo chronoamperometry experiments as we found that it did not interfere with the electrochemical signal of 5-HT as other SSRIs such as fluoxetine or sertraline did. However, fluvoxamineinduced effects observed in such experiments were not specific to it, but also occurred with another SSRI, citalopram, which was also devoid of electrochemical effects on its own (Benmansour et al., 2009).

For chronic studies of AD-like effects, fluvoxamine was not used because it is very expensive such that the cost for chronic administration would be prohibitive; further, is not the Food and Drug Administration (FDA)-approved in the USA for treatment of depression whereas sertraline is. We have selected a dose of sertraline that has been shown not only to downregulate the SERT but also to produce AD-like effects in the FST when given chronically to male rats (Benmansour et al., 1999; Bilge et al., 2008; Furmaga et al., 2011) as well as to female OVX rats (Benmansour et al., 2016).

\section{Experimental Design and Drug Treatment}

In the acute and chronic estradiol experiments, two middleaged groups-10 months and 14 months-were used 2 weeks post-OVX. The impact of the length of hormonal depletion was studied in 10-month OVX rats by measuring effects at 2 weeks and 4 months post-OVX.

In the acute and chronic SSRI experiments, two age groups were used-young adult (4-month) and middle-aged (10 month), with both used 2 weeks post-OVX. The impact of the length of hormonal depletion was studied also in 10-month OVX rats by measuring effects at 2 weeks, 4 months, or 8 months post-OVX.

Therefore, there were the following groups in the acute or chronic experiments:

(1) 4-month OVX, used 2 weeks post-ovariectomy (4m$\mathrm{OVX}+2 \mathrm{w})$

(2) 10-month OVX, used 2 weeks post-ovariectomy (10m$\mathrm{OVX}+2 \mathrm{w})$

(3) 14-month OVX, used 2 weeks post-ovariectomy (14m$\mathrm{OVX}+2 \mathrm{w})$
(4) 10-month OVX, used 4 months post-ovariectomy (10m$\mathrm{OVX}+4 \mathrm{~m})$

(5) 10-month OVX, used 8 months post-ovariectomy (10m$\mathrm{OVX}+8 \mathrm{~m})$

For the chronic estradiol experiments, four cohorts of 1316 rats each were used, 6-8 controls, and 7-8 estradiol-treated animals (groups 2, 3, and 4). Estradiol (5 or $10 \mu \mathrm{g} / \mathrm{day}$ for group 2) and (10 $\mu \mathrm{g} /$ day for groups 3 and 4$)$ was administered for 2 weeks subcutaneously via implantation of osmotic minipumps. Control groups received vehicle which consisted of $25 \% \mathrm{EtOH} / \mathrm{H}_{2} \mathrm{O}$.

For the chronic sertraline experiments, four cohorts of 16 rats each were used, 8 controls and 8 sertraline-treated animals (groups 1, 2, 4, and 5). Sertraline was administered (10 $\mathrm{mg} / \mathrm{kg} /$ day) subcutaneously via implantation of osmotic minipumps. Control groups received vehicle which consisted of $25 \% \mathrm{EtOH} / \mathrm{H}_{2} \mathrm{O}$.

\section{In vivo Chronoamperometry}

This was carried out as described previously (Benmansour et al., 2012).

\section{Animal Preparation}

All groups of Sprague-Dawley OVX rats were anesthetized with chloralose $(70 \mathrm{mg} / \mathrm{kg}) /$ urethane $(700 \mathrm{mg} / \mathrm{kg})$ administered intraperitoneally, after tracheal intubation and placed into a stereotaxic apparatus (David Kopf Instruments). The body temperature of the rat was maintained between 37 and $38^{\circ} \mathrm{C}$ using a water-circulating heating pad. The scalp was incised and reflected and a hole drilled in the skull at the desired coordinates. A small burr hole was drilled over the posterior cortex for placement of $\mathrm{Ag} / \mathrm{AgCl}$ reference electrode.

\section{Electrode Preparation}

Carbon fiber electrodes (30 $\mu \mathrm{m}$ tip diameter, 95-175 $\mu \mathrm{m}$ in length) were coated with Nafion to improve their selectivity, then tested for sensitivity to 5-hydroxyindoleacetic acid (250 $\mu \mathrm{M})$ and calibrated in vitro with 5-HT.

\section{Micropipette Preparation}

The carbon fiber electrode was positioned adjacent to a four barrel micropipette with the tip separation between 250 and $350 \mu \mathrm{m}$. The electrode and the multibarrel micropipette were then attached using sticky wax. Micropipette barrels were filled with 5-HT (200 $\mu \mathrm{M}$, Sigma-Aldrich, St Louis, MO, USA), fluvoxamine (400 $\mu \mathrm{M}$, Sigma-Aldrich, St Louis, MO, USA; fluvoxamine was always used at $4 \times$ the amount of 5-HT applied), or 17- $\beta$-estradiol ( $E_{2}$, Sigma-Aldrich, St Louis, MO, USA). Drugs were prepared in $0.1 \mathrm{M}$ phosphate-buffered saline (PBS) and supplemented with $100 \mu \mathrm{M}$ ascorbic acid. The $\mathrm{pH}$ of all solutions was 7.4. All drugs were delivered by pressure ejection in a volume of 20-100 nl, using a PLI-100 reproducible pico-injector.

\section{Electrochemical Recordings}

The electrode-pipette assembly was lowered into the $\mathrm{CA}_{3}$ region of the hippocampus [stereotaxic coordinates ( $\mathrm{mm}$ ) anterior-posterior, -4.10 from bregma; medio-lateral, +3.30 
from midline; dorsal-ventral, -3.60 from dura; Paxinos and Watson, 1986]. Chronoamperometric recordings were started 20-30 min after the lowering of the assembly to allow the baseline electrochemical signal to stabilize. High-speed chronoamperometric recordings were made using the Fast-16 system (Quanteon). Oxidation potentials consist of $100 \mathrm{~ms}$ pulses of $+0.55 \mathrm{~V}$ versus $\mathrm{Ag} / \mathrm{AgCl}$ were delivered one per second; the electrode was held at the resting potential of $0.0 \mathrm{~V}$ between measurements. Oxidation and reduction currents were digitally integrated during the last $80 \mathrm{~ms}$ of each $100 \mathrm{~ms}$ voltage pulse.

The ability of fluvoxamine to block 5-HT clearance was measured after the 5-HT signal became stable. The effects of estradiol on 5-HT clearance and on fluvoxamine-induced blockade of 5-HT clearance were measured 1-10 $\mathrm{min}$ and 4060 min post- $\mathrm{E}_{2}$ application. Several parameters are obtained from the electrochemical signal produced by exogenous applications of 5-HT. Analyzed in this study is the clearance time parameter, T80 which is the time required for the peak amplitude to be reduced by $80 \%$ (see Figure 1).

\section{Forced Swimming Test}

A modified FST procedure from the one described by Cryan et al. (2002) was used. On day 15 of chronic treatment (while estradiol or sertraline were still administered), a swim test session of $5 \mathrm{~min}$ was carried out with no pretest session. This approach is used in order to avoid the extended delay ( 2 weeks) between the first (pretest) and the second exposure (test) or the impact of drugs being present during the pretest session if pretest and test are separated by the usual $24 \mathrm{~h}$. In addition, it has been shown that positive results with the drugs could be obtained even if no training session was carried out (Cryan et al., 2005; Benmansour et al., 2016). Rats were placed individually into

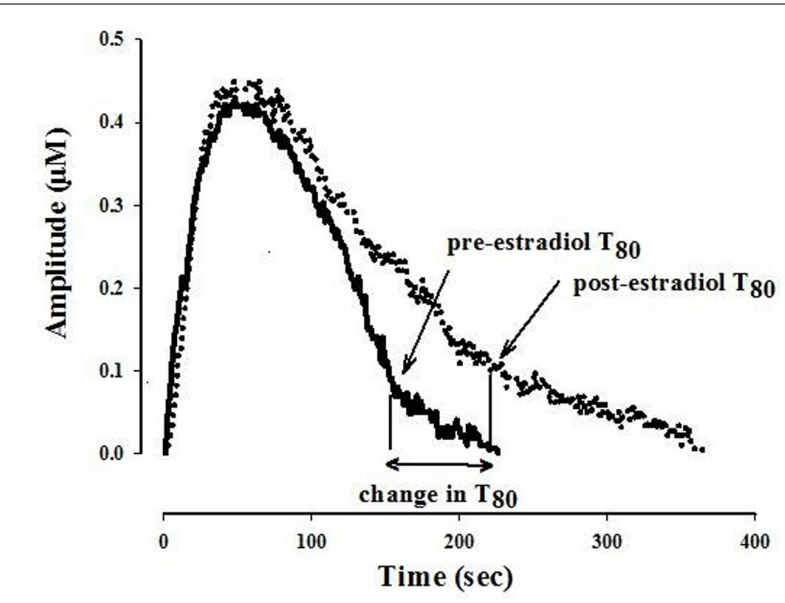

FIGURE 1 | Representative 5-hydroxytryptamine (5-HT) electrochemical signals illustrating the effect of locally applied 17- $\beta$ estradiol into the CA3 region of the hippocampus of an OVX rat. The signal was generated by local application of 5-HT (5.2 pmol). Estradiol $40 \mathrm{pmol}$ was pressure ejected $10 \mathrm{~min}$ before the next application of 5- HT. Shown here is the clearance time, T80 parameter: the time it takes for the peak signal amplitude to be reduced by $80 \%$. For clarity, only oxidation signals are shown. a Plexiglas cylinder $(21 \times 46 \mathrm{~cm})$ filled with $25^{\circ} \mathrm{C}$ water to a depth of $40-\mathrm{cm}$. As the older rats are heavier than the younger ones $(4 \mathrm{~m}-\mathrm{OVX}+2 \mathrm{w}: 295 \pm 2 \mathrm{~g} ; 10 \mathrm{~m}-\mathrm{OVX}+2 \mathrm{w}: 314 \pm 3 \mathrm{~g}$; $14 \mathrm{~m}-\mathrm{OVX}+2 \mathrm{w}: 332 \pm 6 \mathrm{~g} ; 10 \mathrm{~m}-\mathrm{OVX}+4 \mathrm{~m}$ : $362 \pm 10 \mathrm{~g}$; and $10 \mathrm{~m}-$ OVX+8m: $400 \pm 11 \mathrm{~g}$ ) the depth of the water in the tank was adjusted so as not to compromise their swimming in the FST, e.g., $40 \mathrm{~cm}$ instead of $30 \mathrm{~cm}$ such that animals could not place their rear paws on the bottom without being totally submersed. Behaviors during the $5 \mathrm{~min}$ swim were recorded by a video camera positioned above the tank. A time sampling technique was employed whereby the predominant behavior in each $5 \mathrm{~s}$ bin of the test was analyzed. Climbing was defined as upwarddirected movements of the forepaws along the side of the swim chamber. Swimming was defined as active movements (usually horizontal) throughout the swim chamber, which also include crossing into another quadrant. Immobility is assigned when no active movement other than that necessary to keep the rat's head above the water. The rater was blind with respect to the experimental conditions being scored.

\section{Serum Levels of Sertraline and Its Metabolite}

At the end of the FST session serum was collected from all treatment groups. Serum concentrations of sertraline and desmethyl-sertraline were determined by high performance liquid chromatography (HPLC) as described previously (Benmansour et al., 1999).

\section{Statistical Analysis}

Data were analyzed using SigmaStats (Systat Software Inc, San Jose, CA, USA). Kruskal-Wallis one-way analysis of variance (ANOVA) on ranks, followed by Dunn's post hoc analysis was used to compare percent change in T80 values caused either by $\mathrm{E}_{2}$, fluvoxamine, or $\mathrm{E}_{2}$ plus fluvoxamine (Figure 2). Two-way ANOVA followed by Dunnett's analysis was used to compare (1) effect of age or time post-OVX within the vehicle and within the $\mathrm{E}_{2}$ or the sertraline groups, and (2) effect of $\mathrm{E}_{2}$ or sertraline within the age groups and within time post-OVX groups (Figures 3 and 5; Table 1). Paired Student's $t$-test was used when comparing T80 value post-fluvoxamine with T80 value pre-fluvoxamine in the same animal (Figure 4). One-way ANOVA was also used in Figure 4 comparing T80 values pre-fluvoxamine and values postfluvoxamine among all groups. Only when there was a significant main effect and/or interaction effect in the ANOVA's were post hoc analyses carried out. Significance was determined at $p<0.05$.

\section{RESULTS}

\section{Effects of Local Application of Estradiol on SERT Function}

The clearance time parameter, T80, derived from the generated 5 -HT electrochemical signal, was analyzed in this study and is represented in Figure 1. In 4-month OVX rats, $E_{2}(20$ pmol $)$ was shown previously to produce both early (1-10 min post$\left.E_{2}\right)$ and late (40-60 min post- $\left.E_{2}\right)$ effects, i.e., it increased the 


\section{A Effect of estradiol on 5-HT clearance}

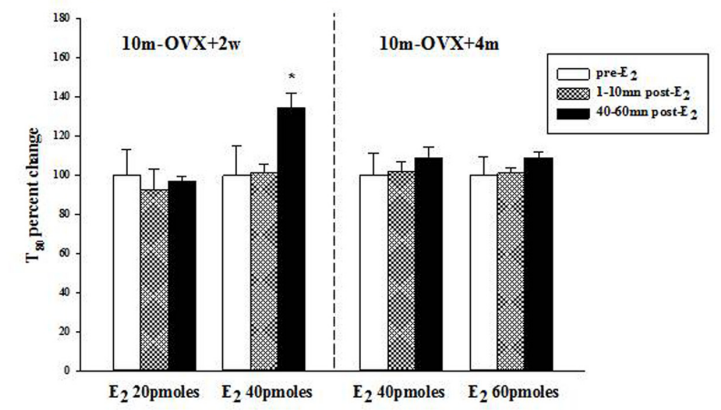

B Effect of estradiol on the ability of fluvoxamine to slow 5-HT clearance

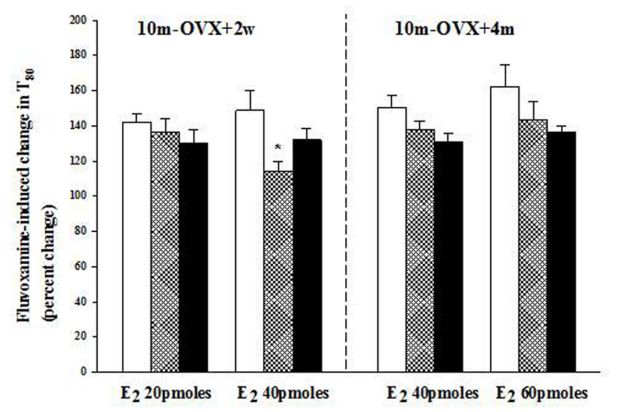

FIGURE 2 | Effects of acute estradiol administration on serotonin transporter (SERT) function in middle-aged OVX rats at different interval times post-OVX. Estradiol (40 or $60 \mathrm{pmol}$ ) was locally applied into the CA3 region of the hippocampus of $10 \mathrm{~m}-\mathrm{OVX}+2 \mathrm{w}$ and $10 \mathrm{~m}-\mathrm{OVX}+4 \mathrm{~m}$ and its effects measured at an early time point (1-10 min) and later time point (40-60 min) post- $\mathrm{E}_{2}$ administration on: (A) 5-HT clearance: the 5-HT clearance time parameter, $T_{80}$, was analyzed pre- $E_{2}, 1-10$ min post- $E_{2}$ and 40-60 min post- $E_{2}$. Bar and brackets represent the $T_{80}$ value as a percentage of the pre-treatment value \pm SEM $(n=7-8)$. ${ }^{*} p<0.05$, Kruskal-Wallis one-way ANOVA on ranks, followed by Dunn's test comparing percent change in $T_{80}$ values 1-10 min and 40-60 min post- $E_{2}$ with the percent change in $T_{80}$ value in the corresponding pre- $E_{2}$ value. (B) The ability of fluvoxamine to slow 5-HT clearance: as shown by an increase in the T80 value. Fluvoxamine ( $4 \times$ the amount of 5-HT) was pressure ejected 60-90 s before the second application of $5-\mathrm{HT}$. Bar and brackets represent the percent change in the $T_{80}$ value after fluvoxamine \pm SEM $(n=6-10)$. ${ }^{*} p<0.05$, Kruskal-Wallis one-way analysis of variance on ranks, followed by Dunn's test comparing percent change in the $T_{80}$ value post-fluvoxamine 1-10 min and 40-60 min after $E_{2}$ with fluvoxamine's percent change in the $T_{80}$ value of the corresponding pre- $E_{2}$ value.

T80 value (a measure of 5-HT clearance) and also blocked the fluvoxamine-induced increase in the T80 value (Benmansour et al., 2009, 2012). At that same dose in 10-month OVX rats, $E_{2}$ had no effect on 5-HT clearance nor did it alter the ability of fluvoxamine to slow 5-HT clearance (Figures 2A,B, left panel). However, a higher dose of $\mathrm{E}_{2}(40 \mathrm{pmol})$ increased the T80 value but this effect was only seen 40-60 min post-application of $E_{2}$ (Figure 2A, left panel). Fluvoxamine significantly increased the T80 value (to $140 \pm 6 \%$ of the control value) in middle aged OVX rats. Administration of $20 \mathrm{pmol}$ of $\mathrm{E}_{2}$ produced no inhibition of the fluvoxamine effect (Figure 2B, left panel). However, the higher amount of $\mathrm{E}_{2}, 40 \mathrm{pmol}$, did reduce significantly the effect of fluvoxamine at 1-10 min after $\mathrm{E}_{2}$ application but not at $40-$ 60 min post- $E_{2}$ (Figure 2B, left panel). By contrast after 4 months of hormonal depletion, $40 \mathrm{pmol} \mathrm{E}_{2}$ had no effect on serotonin clearance nor did it alter the ability of fluvoxamine to slow 5HT clearance in 10-month-old OVX rats. Increasing the dose to $60 \mathrm{pmol}$ also did not produce any effects on the parameters measured (Figures 2A,B, right panel).

\section{Effect of Long-Term Treatment with Estradiol in the FST}

The FST was used to investigate the longer-term effects of $\mathrm{E}_{2}$, administered subcutaneously via osmotic minipumps for 2 weeks. In 4-month OVX rats, it was shown previously that longterm $\mathrm{E}_{2}(5 \mu \mathrm{g})$ induced an AD-like effect in the FST (Benmansour et al., 2016). In 10-month OVX rats, $E_{2}(5 \mu \mathrm{g})$ did not change immobility or swimming behavior in the FST as compared to that measured in control rats (data not shown). At a higher dose $(10 \mu \mathrm{g}), \mathrm{E}_{2}$ induced a significant decrease in immobility that was associated with a significant increase in swimming behavior (Figure 3, first panel). However, $\mathrm{E}_{2}(10 \mu \mathrm{g})$ had no effect in 10 -month OVX rats when the treatment was started 4 months post-OVX as opposed to 2 weeks post-OVX (Figure 3, second panel). By contrast, significant AD-like effects were obtained in 14-month OVX rats tested 2 weeks after OVX (Figure 3, third panel), thereby demonstrating that the lack of AD-like effects of $\mathrm{E}_{2}$ is due to the 4-month hormone withdrawal and not to an age effect.

\section{Effect of Local Application of an SSRI on SERT Function}

This experiment was designed to examine the ability of the SSRI fluvoxamine to inhibit SERT function in 10-month-old middleaged OVX rats in comparison to its effects in 4-month-old adult OVX rats and to determine in the middle-aged rats if the time after OVX when fluvoxamine is tested would influence its effects. As expected, fluvoxamine prolonged the clearance time of 5-HT in $4 \mathrm{~m}-\mathrm{OVX}+2 \mathrm{w}$ rats as shown by a significant increase in the clearance time T80 value post-fluvoxamine compared with the pre-fluvoxamine value (Figure 4). This is consistent with our previous data in young adult OVX rats (Benmansour et al., 2009, 2012 , 2014). Similarly, fluvoxamine significantly increased the T80 value in $10 \mathrm{~m}-\mathrm{OVX}+2 \mathrm{w}, 10 \mathrm{~m}-\mathrm{OVX}+4 \mathrm{~m}$ as well as $10 \mathrm{~m}-$ $\mathrm{OVX}+8 \mathrm{~m}$ when compared to their pre-fluvoxamine T80 values (Figure 4). Thus, fluvoxamine blocked SERT function in all the groups with the effect not dependent on the time elapsed after OVX.

\section{Effect of Chronic Treatment with Sertraline in the FST}

The behavioral effects of chronic treatment with the SSRI sertraline in the FST were examined in young adult and middleaged rats at short or longer times after OVX. As expected and shown previously, in $4 \mathrm{~m}-\mathrm{OVX}+2 \mathrm{w}$ rats, chronic treatment with sertraline induced an AD-like behavior in the FST, i.e., it significantly decreased immobility and increased swimming behaviors as compared to that in control rats. Similarly, chronic 


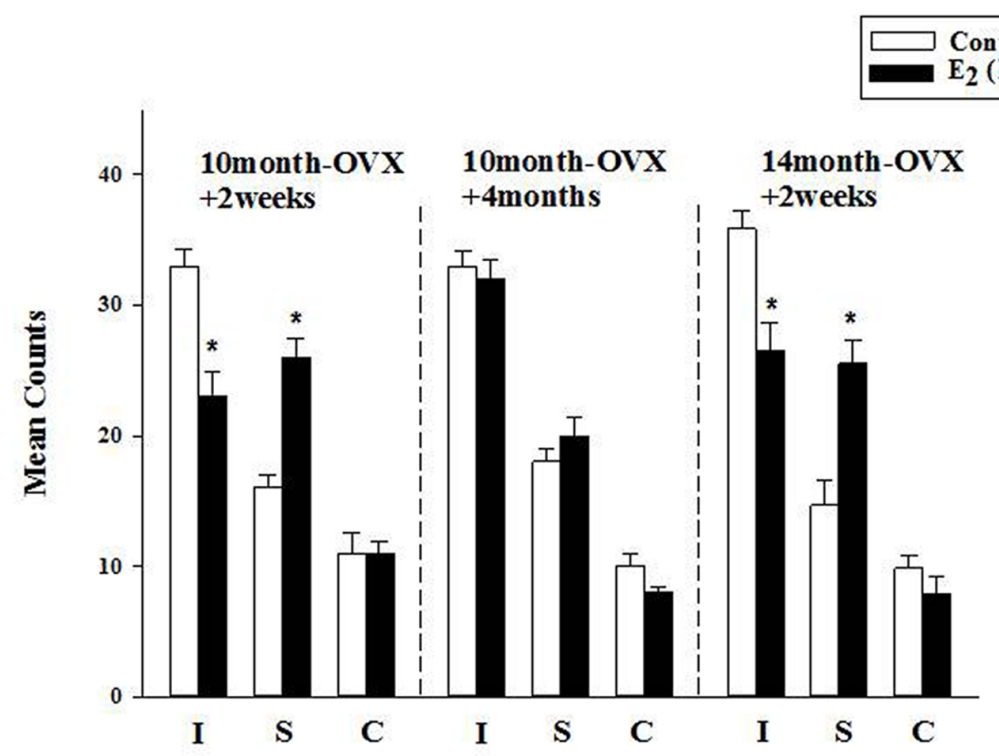

FIGURE 3 | Effect of long-term treatment with estradiol in the FST. OVX rats $(10 \mathrm{~m}-\mathrm{OVX}+2 \mathrm{w}, 10 \mathrm{~m}-\mathrm{OVX}+4 \mathrm{~m}$, and $14 \mathrm{~m}-\mathrm{OVX}+2 \mathrm{w})$ were treated for 2 weeks with estradiol $(10 \mu \mathrm{g})$ via subcutaneous osmotic minipumps, as described in the Section "Materials and Methods." Mean counts for immobility, swimming and climbing behaviors were sampled every $5 \mathrm{~s}$ of the swim test period. Bars and brackets represent the mean value $\pm \mathrm{SEM}, n=6-8 / \mathrm{group}$. Immobility (I): Two-way ANOVAs were carried out between: (1) age and treatment (10m-OVX+2w and 14m-OVX+2w groups) and 2) between time post-OVX and treatment (10m-OVX $+2 \mathrm{w}$, $10 \mathrm{~m}-\mathrm{OVX}+4 \mathrm{~m})$. When comparing age/treatment, two-way ANOVA showed a significant main effect for treatment $\left[F_{(1,24)}=28.23, p<0.001\right]$ but no significant effect for age or for interaction between age $\times$ treatment. When comparing time post-OVX/treatment, two-way ANOVA showed a significant main effects for treatment $\left[F_{(1,26)}=11.47, p<0.01\right]$, for time post-OVX $\left[F_{(1,26)}=8.13, p<0.01\right]$ and for interaction between time post-OVX $\times$ treatment $\left[F_{(1,26)}=8.13\right.$, $p<0.01]$. Dunnett's post hoc analysis was carried out; ${ }^{*} p<0.001$, comparing treatment with $\mathrm{E}_{2}$ within $10 \mathrm{~m}-\mathrm{OVX}+2 \mathrm{w}$ and within $14 \mathrm{~m}-\mathrm{OVX}+2 \mathrm{w}$ with their respective controls. Swimming (S): Two-way ANOVAs were carried out between: (1) age and treatment (10m-OVX+2w and 18m-OVX+2w groups) and (2) between time post-OVX and treatment $(10 \mathrm{~m}-\mathrm{OVX}+2 \mathrm{w}, 10 \mathrm{~m}-\mathrm{OVX}+4 \mathrm{~m})$. When comparing age/treatment, two-way ANOVA showed a significant main effect for treatment $\left[F_{(1,24)}=46.18, p<0.001\right]$ but no significant effect for age or for interaction between age $\times$ treatment. When comparing time post-OVX/treatment, two-way ANOVA showed a significant main effects for treatment $\left[F_{(1,26)}=24.39, p<0.001\right]$ and for interaction between time post-OVX $\times$ treatment $\left[F_{(1,26)}=8.68\right.$, $p<0.01$ but no effect for time post-OVX. Dunnett's post hoc analysis was carried out; ${ }^{*} p<0.001$, comparing treatment with $\mathrm{E}_{2}$ within $10 \mathrm{~m}-\mathrm{OVX}+2 \mathrm{~W}$ and within $14 \mathrm{~m}-\mathrm{OVX}+2 \mathrm{w}$ with their respective controls. Climbing (C): Two-way ANOVAs were carried out between age and treatment and between time post-OVX and treatment. There were no significant effects in any of the analyses.

treatment with sertraline significantly decreased immobility and increased swimming behaviors in middle-aged rats at 2 weeks, 4 months, or 8 months post-OVX (Figure 5). None of the treatments altered climbing behavior. Although there was a trend for the effects of sertraline (on both immobility and swimming) to be of smaller magnitude in the $10 \mathrm{~m}-\mathrm{OVX}+4 \mathrm{~m}$ and the $10 \mathrm{~m}$ $\mathrm{OVX}+8 \mathrm{~m}$ than the other groups, this difference did not reach significance. There was no change in baseline behavior within groups (Figure 5).

In addition serum levels of sertraline and its metabolite desmethyl-sertraline were analyzed in each group after conclusion of the FST. Neither sertraline levels nor the ratio of desmethyl-sertraline/sertraline were significantly different in any of the experimental groups. Although there was a trend for both measurements to be higher in the $10 \mathrm{~m}-\mathrm{OVX}+4 \mathrm{~m}$ than any of the other groups, this was not statistically significant (Table 1).

\section{DISCUSSION}

These data show that (1) a higher dose of estradiol was necessary to induce AD-like effects in middle-aged OVX rats as compared to those needed in young adult OVX rats; (2) treatment with SSRIs induced an AD-like effect in the middle-aged OVX rats that was similar to that seen in younger adult OVX rats; (3) AD-like effects of estradiol are dependent on the time interval post-ovariectomy whereas the effects of SSRIs are not. Moreover, such results are similar irrespective of whether they were obtained using chronoamperometry to measure SERT function directly in the CA3 region of the hippocampus or the FST to measure it indirectly.

Sensitivity to acute as well as long-term treatment with estradiol decreased with age in OVX rats (Figures 2 and 3). This has been demonstrated previously. Whereas acute treatment with estradiol both at 5 and $10 \mu \mathrm{g}$ produced an AD-like effect in 3-month-old OVX rats, only $10 \mu \mathrm{g}$ had an effect in 14-monthold OVX rats (Recamier-Carballo et al., 2012). In addition, differences exist in the acute effects of $\mathrm{E}_{2}$ in the younger and older rats. In young adult OVX rats, $\mathrm{E}_{2}$ had both rapid as well as effects that were manifest at a later time on both slowing 5 -HT clearance and on blocking the ability of fluvoxamine to slow 5-HT clearance (Benmansour et al., 2009, 2012). The AD-like effect of $E_{2}$ (i.e., blockade of 5-HT clearance) is due to $\mathrm{ER} \beta$ activation whereas $\mathrm{E}_{2}$ 's inhibition of fluvoxamine's ability to slow serotonin clearance is 


\section{Effect of fluvoxamine on 5-HT clearance}

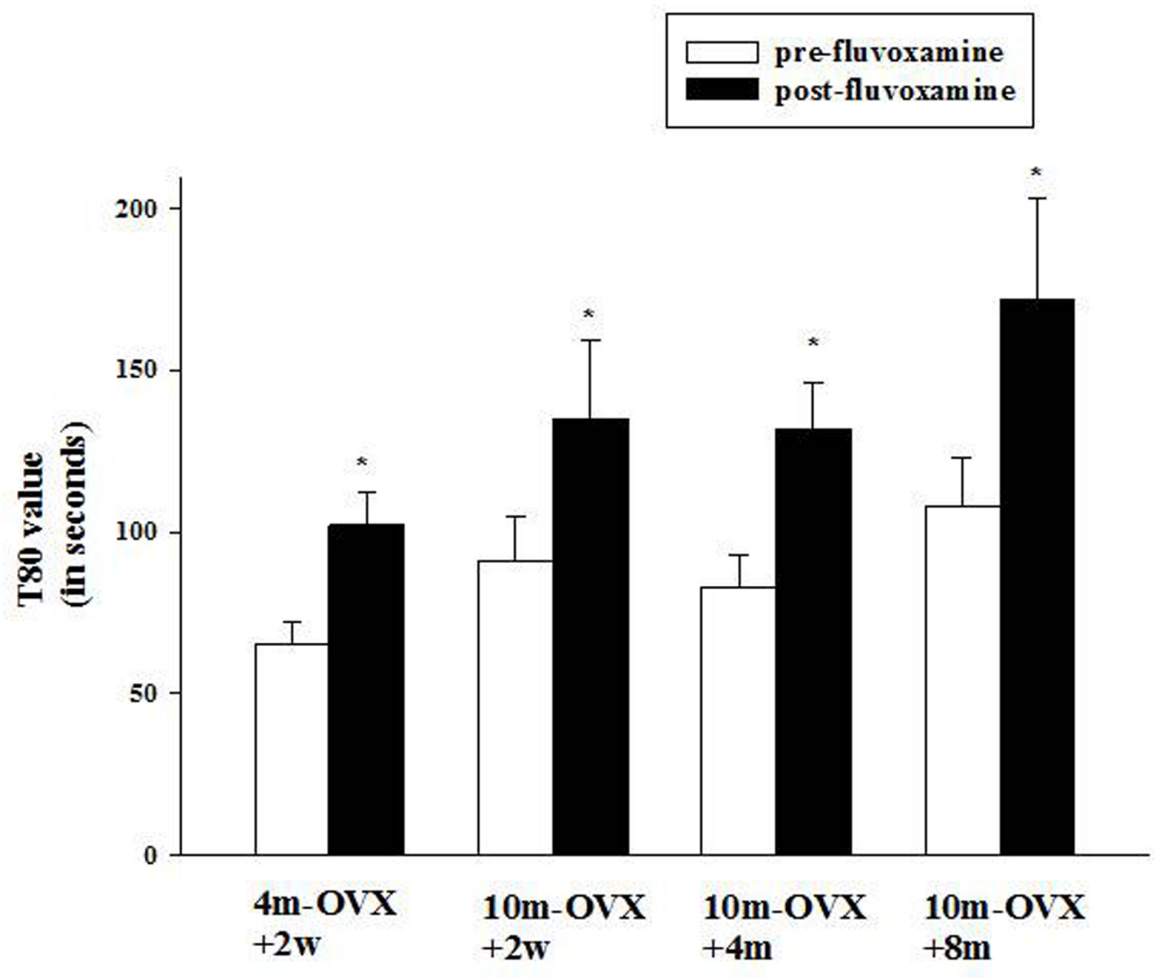

FIGURE 4 | Effects of acute fluvoxamine on SERT function of young adult OVX rat or middle-aged OVX rats at different interval times post-OVX. Electrochemical recordings were carried out in the CA3 region of the hippocampus of $4 \mathrm{~m}-\mathrm{OVX}+2 \mathrm{w}, 10 \mathrm{~m}-\mathrm{OVX}+2 \mathrm{w}, 10 \mathrm{~m}-\mathrm{OVX}+4 \mathrm{~m}, 10 \mathrm{~m}-\mathrm{OVX}+8 \mathrm{~m}$. Fluvoxamine ( $4 \times$ the amount of 5-HT) was pressure ejected 60-90 s before the second application of 5-HT. Bar and brackets represent mean T80 value (in seconds) before and after fluvoxamine application \pm SEM $(n=6-9)$; * $p<0.01$, paired Student's $t$-test comparing post-fluvoxamine value with pre-fluvoxamine value for each group. One-way ANOVA comparing T80 values pre-fluvoxamine and post-fluvoxamine values in all groups reveals no differences among groups in these two values.

mediated through the ER $\alpha$ receptor subtype (Benmansour et al., 2012). In middle-aged OVX rats, the effects of $E_{2}$ on fluvoxamineinduced blockade of 5-HT clearance were rapid whereas its own effects on 5-HT clearance were manifest later in time (Figure 2).

Several mechanisms could explain these differential effects as well as the reduced sensitivity to estradiol with aging, e.g., subcellular redistribution of $\mathrm{ER} \alpha$ and $\mathrm{ER} \beta$ in middle age and/or an age-dependent decline in the number of available ERs. Studies using aged female animals have shown that the expression of both $\mathrm{ER} \alpha$ and $\mathrm{ER} \beta$ in the brain change with age in a region specific manner for each receptor subtype (Foster, 2012); however, both ER subunit proteins decreased in the hippocampus of aged female rats (Yamaguchi and Yuri, 2014). This could account, at least partially, for the reduced potency of estradiol observed in our experiments using chronoamperometry. In addition to the agerelated changes in ER expression, the ability of estrogen to regulate ER expression changes with age and is different in each brain area for each ER subtype (Yamaguchi and Yuri, 2014). It is also possible that a decline in $\mathrm{ER} \alpha$ function, rather than a loss of receptor expression, could mediate a decrease in estrogen's effects with advanced age. Aging was shown to be associated with the expression of dominant-negative ER $\alpha$ splice variants that reduced the ability of estradiol treatments to preserve cognition (Bohacek and Daniel, 2009). Little is known how ER expression changes in the hippocampus of aging humans. However, and importantly, elderly women are more likely to express ER $\alpha$ splice variants that can act as dominant negative regulators, reducing or inhibiting $\mathrm{ER} \alpha$-mediated transcriptional activity (Ishunina and Swaab, 2009).

Similarly, several ER $\beta$ splice variants have been identified in the rat hippocampus. One of these, $\operatorname{rER} \beta 2$, has a low binding affinity for estradiol and the ability to interact with coactivators such that it functions as a dominant negative receptor in the rat (Weiser et al., 2008). rER $\beta 2$ expression increased in the brains of intact rats with age and estropause (Wang et al., 2012). Finally, estrogen signaling possibly involving either cAMP response element-binding protein (CREB) or extracellular signal-regulated kinases (ERK), also changes with age. Age-related decreases in rapid $E_{2}$ responses are observed for $E_{2}$-mediated growth in synaptic transmission and facilitation of long-term potentiation (Foy et al., 2008), and activation of ERK (Bi et al., 2003). Also, the levels of total or phosphorylated CREB are reduced in the hippocampus of old rats (Kudo et al., 2005). The effect of aging on CREB seems to be specific for the hippocampus because 


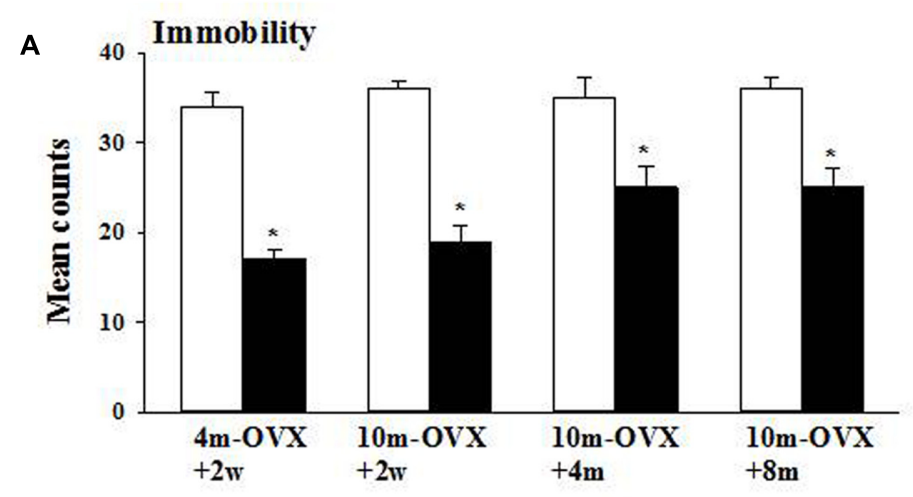

B
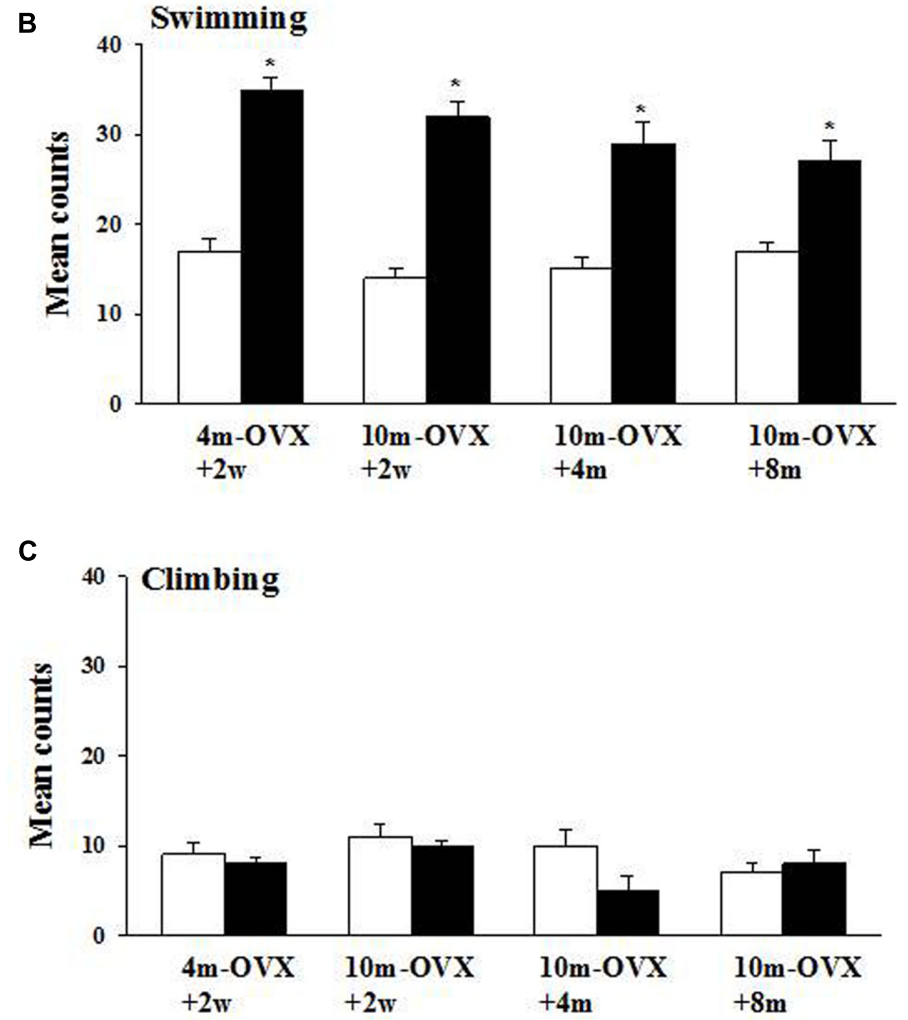

FIGURE 5 | Effect of chronic treatment with sertraline in the FST. OVX rats (4m-OVX+2w, 10m-OVX+2w, 10m-OVX+4m, $10 \mathrm{~m}-\mathrm{OVX}+8 \mathrm{~m})$ were treated for 2 weeks with sertraline via subcutaneous osmotic minipumps, as described in the Section "Materials and Methods." Mean counts for immobility, swimming and climbing behaviors were sampled every $5 \mathrm{~s}$ of the swim test period. Bars and brackets represent the mean value $\pm \mathrm{SEM}, n=8 / \mathrm{group}$. (A) Immobility: Two-way ANOVAs were carried out between: (1) age and treatment (4m-OVX+2w and 10m-OVX $+2 \mathrm{w}$ groups) and (2) between time post-OVX and treatment (10m-OVX+2w, $10 \mathrm{~m}-\mathrm{OVX}+4 \mathrm{~m}$, and 10m-OVX+8m groups). When comparing age/treatment, two-way ANOVA showed a significant main effect for treatment $\left[F_{(1,28)}=169.53\right.$, $p<0.001$ ] but no significant effect for age or for interaction between age $\times$ treatment. When comparing time post-OVX/treatment, two-way ANOVA showed a significant main effect for treatment $\left[F_{(1,42)}=70.48, p<0.001\right]$ but no significant effect for time post-OVX or for interaction between time post-OVX $\times$ treatment. Dunnett's post hoc analysis was carried out; ${ }^{*} p<0.001$, comparing $10 \mathrm{~m}-\mathrm{OVX}+2 \mathrm{w}$ with $4 \mathrm{~m}-\mathrm{OVX}+2 \mathrm{w}$ and $10 \mathrm{~m}-\mathrm{OVX}+4 \mathrm{~m}$ and $10 \mathrm{~m}-\mathrm{OVX}+8 \mathrm{~m}$ with $10 \mathrm{~m}-\mathrm{OVX}-2$ weeks. (B) Swimming: Two-way ANOVAs were carried out between (1) age and treatment (4m-OVX+2w and 10m-OVX+2w groups) and (2) between time post-OVX and treatment $(10 \mathrm{~m}-\mathrm{OVX}+2 \mathrm{w}, 10 \mathrm{~m}-\mathrm{OVX}+4 \mathrm{~m}$, and 10m-OVX+8m groups). When comparing age/treatment, two-way ANOVA showed a significant main effect for age $\left[F_{(1,28)}=5.24, p<0.05\right]$ and for treatment $\left[F_{(1,28)}=178.80, p<0.001\right]$ but no significant effect for interaction between age $\times$ treatment. When comparing time post-OVX/treatment, two-way ANOVA showed a significant main effect for treatment $\left[F_{(1,42)}=70.48, p<0.001\right]$ but no significant effect for time post-OVX or for interaction between time post-OVX $\times$ treatment. Dunnett's post hoc analysis was carried out; ${ }^{*} p<0.001, \mathrm{comparing} 10 \mathrm{~m}-\mathrm{OVX}+2 \mathrm{w}$ with $4 \mathrm{~m}-\mathrm{OVX}+2 \mathrm{w}$ and $10 m-O V X+4 m$ and $10 m-O V X+8 m$ with $10 m-O V X-2$ weeks. (C) Climbing: Two-way ANOVAs were carried out between age and treatment and between time post-OVX and treatment. There were no significant effects in any of the analyses. 
TABLE 1 | Serum levels of sertraline.

\begin{tabular}{|c|c|c|c|c|}
\hline & $4 m-O V X+2 w$ & $10 \mathrm{~m} \mathrm{OVX}+2 \mathrm{w}$ & $10 m-O V X+4 m$ & $10 m-O V X+8 m$ \\
\hline Sertraline (ng/ml) & $316^{a} \pm 28$ & $355 \pm 46$ & $609 \pm 165$ & $238 \pm 29$ \\
\hline Desmethyl-sertraline/sertraline (as a ratio) & $0.416 \pm 0.07$ & $0.533 \pm 0.04$ & $0.644 \pm 0.05$ & $0.472 \pm 0.06$ \\
\hline
\end{tabular}

a Mean \pm SEM.

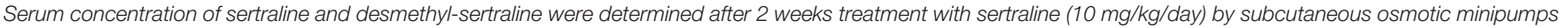
implant. Also represented in the table is the ratio of desmethyl-sertraline/sertraline.

A two-way ANOVA analysis age/treatment and time post-OVX/treatment revealed no significant effect.

changes in PCREB were not observed in the frontal cortex of old rats (Xu et al., 2010). All these factors, then, may be in play in accounting for our observations of diminished effects of estradiol in 10-month OVX rats as compared to younger OVX rats.

Studies on the effect of AD treatment using older female animals are scarce, with most having tested only the effects of acute treatment with ADs. Consistent with our data, acute fluoxetine $(10 \mathrm{mg} / \mathrm{kg})$ treatment produced an analogous response in young adult and middle-aged OVX rats in the FST, although a lower dose $2.5 \mathrm{mg} / \mathrm{kg}$ reduced immobility in younger rats but not in middle-aged females (Recamier-Carballo et al., 2012; Fernandez-Guasti et al., 2016). In contrast, citalopram (up to $10 \mathrm{mg} / \mathrm{kg}$ ) given sub-acutely to middle-aged OVX rats had no effect in the FST (Vega Rivera et al., 2016), although it did produce an AD-like effect in middle-aged OVX rats that had been subjected to chronic mild stress (Romano-Torres and FernandezGuasti, 2010). Chronic treatment with fluoxetine had no effect in middle-aged female mice (Li et al., 2015).

Modulation of 5-HT neurotransmission has long been a primary pharmacological target for the treatment of depression and more recently anxiety disorders by SSRIs. SSRIs enhance synaptic 5-HT action by blocking the reuptake of 5-HT (Schloss and Williams, 1998). Global enhancement of serotonin neurotransmission may activate all subtypes of serotonin receptors in brain, whereas each 5-HT receptor subtype has different and specific functions in defined brain regions (Polter and Li, 2011). The process of aging has complex effects on 5-HT neurotransmission throughout central and peripheral systems. Although there are no clear alterations in the number of 5-HT neurons, accumulated evidence suggests aging compromises 5HT neurotransmission as well as producing altered expression of SERT and 5-HT receptors in multiple brain regions (Rodriguez et al., 2012; Fidalgo et al., 2013). Contradictory results have been reported on age-related changes in SERT, with decreases, increases or no change being described (Brunello et al., 1985; Severson et al., 1985; Owen et al., 1986; Marcusson et al., 1987; Arranz et al., 1993; Yamamoto et al., 2002). Multiple studies have demonstrated a decrease in serotonin receptor 1A (5-HT1A), serotonin receptor $2 \mathrm{~A}$ (5-HT2A) receptor binding sites/affinity, protein expression and/or gene expression in the brain with increasing age (Meltzer et al., 1998, 2001; Tauscher et al., 2001); however, this has not always been replicated (Parsey et al., 2002). This variability could be due to the species, the brain area or the measurement techniques used to quantify SERT and/or 5HT receptors (Rodriguez et al., 2012). Little is known, however, about age-related changes in serotonergic function in females. In this study, the effect of local application of an SSRI into the CA3 region of the hippocampus on SERT function was similar in young adult and middle-aged OVX rats (Figure 4). Also similar was the effect of sertraline in the FST in all the groups (Figure 5). Thus, two different measures of the effect of SSRIs on SERT function gave the same result, namely that effects were similar in younger and middle aged OVX rats. Pharmacokinetic changes produced by age could modify the drug effects. The most significant change is an age-dependent reduction of renal excretion, caused by deficient glomerular filtration (Turnheim, 2003; Mangoni and Jackson, 2004). As a consequence, drug serum levels tend to increase, producing a stronger pharmacological effect. This was not the case in our study as in middle-aged OVX rats levels of sertraline and its metabolite were not significantly different from those measured in younger OVX rats (Table 1).

Clinical data have been equivocal whether estrogen therapy in postmenopausal women benefits cognition (Maki, 2012; Daniel, 2013). A reevaluation of the role of estrogens as neuroprotective agents led to the development of "the critical period" or "window of opportunity" hypothesis of estrogen effects (Rocca et al., 2011). This proposes that estrogen therapy is only beneficial if administration is begun during a time window in close proximity to menopause (Resnick and Henderson, 2002). An initial study in rats provided the first suggestion of a critical period for the efficacy of estrogen (Gibbs, 2000). Initiation of estradiol treatment immediately or 3 months following ovariectomy in middle-aged rats enhanced performance on a delayed matchingto-position maze task whereas no enhancement of performance was evident if estradiol administration was begun 10 months after ovariectomy (Gibbs, 2000). Other data also indicated that beneficial effects of estradiol on cognition, cholinergic function, and hippocampal plasticity were obtained only when hormone treatment was initiated at relatively early time points after ovariectomy (Daniel, 2013).

Many studies have examined the critical period hypothesis with respect to cognition but only a few clinical studies have investigated the effect of the time of initiation of ERT and/or AD therapy after menopause in mood disorders (see Craig, 2013). It was reported that ERT improved mood in pre-menopausal but not post-menopausal women (Cohen et al., 2003). There have been very few preclinical studies as well. A recent study showed that an AD-like effect induced by acute treatment with ethinylestradiol treatment was found after 1 week but not 3 weeks postOVX (Fernandez-Guasti et al., 2016). In middle-aged OVX rats, estradiol had an AD-like effect in the FST when given at a short time post-OVX but not when given 5-6 months later (Walf et al., 2009; Kiss et al., 2012; Wang et al., 2012). Consistent with this, our 
data show that the $\mathrm{AD}$-like effect of estradiol in middle aged rats was present only when treatment was started 2 weeks post-OVX but not 4 months post-OVX (Figures 2 and 3 ). In addition, this effect was confirmed to be due to the longer time interval postOVX and not to aging as 14-month OVX rats displayed an ADlike effect when tested 2 weeks post-OVX in the FST (Figure 3). Emerging data implicate a decline in ER $\alpha$ expression or function in brain resulting from long-term hormone deprivation as a basis for the existence of the critical period (Foster, 2012). In addition it was suggested that the $\mathrm{C}$ terminus of Hsc70-interacting proteinmediated degradation of hippocampal $\mathrm{ER} \alpha$ may serve as a molecular mechanism for the critical therapeutic window for post-menopausal estrogen therapy (Zhang et al., 2011). Another potential mechanism may be due to increased expression of the dominant negative $\operatorname{ER} \beta$ isoform, $\mathrm{ER} \beta 2$, which correlated with a significant decrease in swim time in the FST and appears to be a crucial determinant responsible, at least in part, for the loss of estrogen response after protracted absence of ovarian hormones in a rat model of menopause (Wang et al., 2012). Experiments examining such parameters will be necessary to determine the mechanisms responsible for the results obtained here after either acute or chronic treatment with estradiol.

This study also examined if prolonged estrogen deprivation may reduce the likelihood of SSRIs having an $\mathrm{AD}$-like effect. It was found that SSRIs have the same efficacy at blocking SERT function and inducing AD-like effects in the middle-aged OVX rats tested 2 weeks, 4 months, or 8 months post-OVX (Figures 4 and 5). Only a few studies have investigated the critical window for $\mathrm{AD}$ effects in middle-aged rats as opposed to younger OVX rats. In one study, acute citalopram treatment had no effect in the FST in middle aged-rats independent of the post OVX interval. The authors concluded that age and endocrine condition are factors that contribute to decreased sensitivity to citalopram (Vega Rivera et al., 2016). Treatment with fluoxetine was reported to be efficacious in depressed middle-aged women (Amsterdam et al., 1999) and that pre- and post-menopausal women suffering from depression both responded to citalopram treatment (Kornstein et al., 2013). However, a poorer response to $\mathrm{AD}$ treatment in post-menopausal women compared to premenopausal women has also been reported (Pae et al., 2009).

\section{CONCLUSION}

This study showed that the sensitivity to estradiol decreased in middle-aged OVX rats compared to younger adult OVX rats, whereas the $\mathrm{AD}$-like effects of SSRIs was not diminished

\section{REFERENCES}

Amsterdam, J., Garcia-Espana, F., Fawcett, J., Quitkin, F., Reimherr, F., Rosenbaum, J., et al. (1999). Fluoxetine efficacy in menopausal women with and without estrogen replacement. J. Affect. Disord. 55, 11-17. doi: 10.1016/S01650327(98)00203-1

Anderson, R. A., Themmen, A. P., Al-Qahtani, A., Groome, N. P., and Cameron, D. A. (2006). The effects of chemotherapy and long-term gonadotrophin suppression on the ovarian reserve in premenopausal women with breast cancer. Hum. Reprod. 21, 2583-2592. doi: 10.1093/humrep/del201 in middle-aged OVX rats compared to young adult OVX rats. The AD-like effect of estradiol, in contrast to that of SSRIs, is subject to a critical period. In addition despite the potential benefits of estradiol treatment, hormone replacement therapy presents unwanted health risks, particularly in older postmenopausal women (Lukes, 2008). Findings from the Women's Health Initiative trial show that HRT in healthy postmenopausal women is associated with an elevated risk of breast cancer and coronary heart disease (Rossouw et al., 2002). In addition, the risk of breast cancer increases with longer exposure to HRT, limiting long-term use (Rossouw et al., 2002; Anderson et al., 2006). An additional disadvantage of estradiol treatment is that estradiol act as a non-selective ER agonist. $\mathrm{ER} \alpha$ and $\mathrm{ER} \beta$ appear to have opposing functions in several brain areas. As shown previously, ER $\beta$ mediates the AD-like effect of estradiol whereas ER $\alpha$ mediates its blockade of the AD-like effect of SSRIs (Benmansour et al., 2012); and that could result in diminishing therapeutic potential of estradiol. Thus, if our results in rats can be translated to the clinical situation, they indicate that SSRIs have essentially identical effects on the SERT in females regardless of age and the time of treatment initiation after menopause. However, if estradiol is to be tried in postmenopausal women suffering from depression, our results suggest that it might only be helpful to those in perimenopause or shortly after menopause begins.

\section{AUTHOR CONTRIBUTIONS}

SB contributed to the design, acquisition and interpretation of the data, and the draft of the manuscript. LA contributed to the acquisition and interpretation of the data and helped draft the manuscript. AF contributed to data analysis, interpretation, and provided intellectual contribution during drafting of the manuscript.

\section{FUNDING}

This research was supported by funds from NARSAD and the Department of Veterans Affairs.

\section{ACKNOWLEDGMENT}

We thank Dr. Martin A. Javors for measurement of serum concentration of sertraline and desmethyl-sertraline.

Arranz, B., Eriksson, A., Mellerup, E., Plenge, P., and Marcusson, J. (1993). Effect of aging in human cortical pre- and postsynaptic serotonin binding sites. Brain Res. 620, 163-166. doi: 10.1016/0006-8993(93)90286-V

Benmansour, S., Adeniji, O. S., Privratsky, A. A., and Frazer, A. (2016). Effects of long-term treatment with estradiol and estrogen receptor subtype agonists on serotonergic function in ovariectomized rats. Neuroendocrinology 103, 269281. doi: $10.1159 / 000437268$

Benmansour, S., Cecchi, M., Morilak, D. A., Gerhardt, G. A., Javors, M. A., Gould, G. G., et al. (1999). Effects of chronic antidepressant treatments on serotonin transporter function, density, and mRNA level. J. Neurosci. 19, 10494-10501. 
Benmansour, S., Piotrowski, J. P., Altamirano, A. V., and Frazer, A. (2009). Impact of ovarian hormones on the modulation of the serotonin transporter by fluvoxamine. Neuropsychopharmacology 34, 555-564. doi: 10.1038/npp.2008.23

Benmansour, S., Privratsky, A. A., Adeniji, O. S., and Frazer, A. (2014). Signaling mechanisms involved in the acute effects of estradiol on 5-HT clearance. Int. J. Neuropsychopharmacol. 17, 765-777. doi: 10.1017/S146114571300165X

Benmansour, S., Weaver, R. S., Barton, A. K., Adeniji, O. S., and Frazer, A. (2012). Comparison of the effects of estradiol and progesterone on serotonergic function. Biol. Psychiatry 71, 633-641. doi: 10.1016/j.biopsych.2011. 11.023

Bestetti, G. E., Reymond, M. J., Blanc, F., Boujon, C. E., Furrer, B., and Rossi, G. L. (1991). Functional and morphological changes in the hypothalamo-pituitarygonadal axis of aged female rats. Biol. Reprod. 45, 221-228. doi: 10.1095/ biolreprod45.2.221

Bi, R., Foy, M. R., Thompson, R. F., and Baudry, M. (2003). Effects of estrogen, age, and calpain on MAP kinase and NMDA receptors in female rat brain. Neurobiol. Aging 24, 977-983. doi: 10.1016/S0197-4580(03)00012-5

Bilge, S., Bozkurt, A., Bas, D. B., Aksoz, E., Savli, E., Ilkaya, F., et al. (2008). Chronic treatment with fluoxetine and sertraline prevents forced swimming test-induced hypercontractility of rat detrusor muscle. Pharmacol. Rep. 60, 872-879.

Blazer, D. G. (2003). Depression in late life: review and commentary. J. Gerontol. A Biol. Sci. Med. Sci. 58, 249-265. doi: 10.1093/gerona/58.3.M249

Bohacek, J., and Daniel, J. M. (2009). The ability of oestradiol administration to regulate protein levels of oestrogen receptor alpha in the hippocampus and prefrontal cortex of middle-aged rats is altered following long-term ovarian hormone deprivation. J. Neuroendocrinol. 21, 640-647. doi: 10.1111/j.13652826.2009.01882.x

Brunello, N., Riva, M., Volterra, A., and Racagni, G. (1985). Age-related changes in 5 HT uptake and $[3 \mathrm{H}]$ imipramine binding sites in rat cerebral cortex. Eur. J. Pharmacol. 110, 393-394. doi: 10.1016/0014-2999(85)90573-4

Castrén, E., and Rantamäki, T. (2010). The role of BDNF and its receptors in depression and antidepressant drug action: reactivation of developmental plasticity. Dev. Neurobiol. 70, 289-297. doi: 10.1002/dneu.20758

Chakraborty, T. R., and Gore, A. C. (2004). Aging-related changes in ovarian hormones, their receptors, and neuroendocrine function. Exp. Biol. Med. (Maywood) 229, 977-987.

Cohen, L. S., Soares, C. N., Poitras, J. R., Prouty, J., Alexander, A. B., and Shifren, J. L. (2003). Short-term use of estradiol for depression in perimenopausal and postmenopausal women: a preliminary report. Am. J. Psychiatry 160, 1519-1522. doi: 10.1176/appi.ajp.160.8.1519

Craig, M. C. (2013). Should psychiatrists be prescribing oestrogen therapy to their female patients? Br. J. Psychiatry 202, 9-13. doi: 10.1192/bjp.bp.111.102855

Cryan, J. F., Markou, A., and Lucki, I. (2002). Assessing antidepressant activity in rodents: recent developments and future needs. Trends Pharmacol. Sci. 23, 238-245. doi: 10.1016/S0165-6147(02)02017-5

Cryan, J. F., Page, M. E., and Lucki, I. (2005). Differential behavioral effects of the antidepressants reboxetine, fluoxetine, and moclobemide in a modified forced swim test following chronic treatment. Psychopharmacology (Berl) 182, 335-344. doi: 10.1007/s00213-005-0093-5

Daniel, J. M. (2013). Estrogens, estrogen receptors, and female cognitive aging: the impact of timing. Horm. Behav. 63, 231-237. doi: 10.1016/j.yhbeh.2012.05.003

Daws, L. C., Toney, G. M., Gerhardt, G. A., and Frazer, A. (1998). In vivo chronoamperometric measures of extracellular serotonin clearance in rat dorsal hippocampus: contribution of serotonin and norepinephrine transporters. J. Pharmacol. Exp. Ther. 286, 967-976.

Duman, R. S., and Li, N. (2012). A neurotrophic hypothesis of depression: role of synaptogenesis in the actions of NMDA receptor antagonists. Philos. Trans. $R$. Soc. Lond. B Biol. Sci. 367, 2475-2484. doi: 10.1098/rstb.2011.0357

Fernandez-Guasti, A., Olivares-Nazario, M., Reyes, R., and Martinez-Mota, L. (2016). Sex and age differences in the antidepressant-like effect of fluoxetine in the forced swim test. Pharmacol. Biochem. Behav. doi: 10.1016/j.pbb.2016.01. 011 [Epub ahead of print].

Fidalgo, S., Ivanov, D. K., and Wood, S. H. (2013). Serotonin: from top to bottom. Biogerontology 14, 21-45. doi: 10.1007/s10522-012-9406-3

Foster, T. C. (2012). Role of estrogen receptor alpha and beta expression and signaling on cognitive function during aging. Hippocampus 22, 656-669. doi: 10.1002/hipo.20935
Foy, M. R., Baudry, M., Foy, J. G., and Thompson, R. F. (2008). 17beta-estradiol modifies stress-induced and age-related changes in hippocampal synaptic plasticity. Behav. Neurosci. 122, 301-309. doi: 10.1037/0735-7044.122.2.301

Frey, B. N., Lord, C., and Soares, C. N. (2008). Depression during menopausal transition: a review of treatment strategies and pathophysiological correlates. Menopause Int. 14, 123-128. doi: 10.1258/mi.2008.008019

Furmaga, H., Shah, A., and Frazer, A. (2011). Serotonergic and noradrenergic pathways are required for the anxiolytic-like and antidepressant-like behavioral effects of repeated vagal nerve stimulation in rats. Biol. Psychiatry 70, 937-945. doi: 10.1016/j.biopsych.2011.07.020

Gareri, P., Falconi, U., De Fazio, P., and De Sarro, G. (2000). Conventional and new antidepressant drugs in the elderly. Prog. Neurobiol. 61, 353-396. doi: 10.1016/S0301-0082(99)00050-7

Gibbs, R. B. (2000). Long-term treatment with estrogen and progesterone enhances acquisition of a spatial memory task by ovariectomized aged rats. Neurobiol. Aging 21, 107-116. doi: 10.1016/S0197-4580(00)00103-2

Gore, A. C., Yeung, G., Morrison, J. H., and Oung, T. (2000). Neuroendocrine aging in the female rat: the changing relationship of hypothalamic gonadotropin-releasing hormone neurons and N-methyl-D-aspartate receptors. Endocrinology 141, 4757-4767. doi: 10.1210/endo.141.12.7841

Huang, C. C., Wei, I. H., Chou, Y. H., and Su, T. P. (2008). Effect of age, gender, menopausal status, and ovarian hormonal level on rTMS in treatment-resistant depression. Psychoneuroendocrinology 33, 821-831. doi: 10.1016/j.psyneuen. 2008.03.006

Ishunina, T. A., and Swaab, D. F. (2009). Hippocampal estrogen receptor-alpha splice variant TADDI in the human brain in aging and Alzheimer's disease. Neuroendocrinology 89, 187-199. doi: 10.1159/000158573

Jacobs, B. L., and Azmitia, E. C. (1992). Structure and function of brain serotonin system. Physiol. Rev. 72, 165-229.

Kasper, S., de Swart, H., and Friis Andersen, H. (2005). Escitalopram in the treatment of depressed elderly patients. Am. J. Geriatr. Psychiatry 13, 884-891. doi: 10.1097/00019442-200510000-00008

Kiss, A., Delattre, A. M., Pereira, S. I., Carolino, R. G., Szawka, R. E., AnselmoFranci, J. A., et al. (2012). 17beta-estradiol replacement in young, adult and middle-aged female ovariectomized rats promotes improvement of spatial reference memory and an antidepressant effect and alters monoamines and BDNF levels in memory- and depression-related brain areas. Behav. Brain Res. 227, 100-108. doi: 10.1016/j.bbr.2011.10.047

Kornstein, S. G., Clayton, A. H., Bao, W., and Guico-Pabia, C. J. (2015). A pooled analysis of the efficacy of desvenlafaxine for the treatment of major depressive disorder in perimenopausal and postmenopausal women. J. Womens Health (Larchmt) 24, 281-290. doi: 10.1089/jwh.2014.4900

Kornstein, S. G., Toups, M., Rush, A. J., Wisniewski, S. R., Thase, M. E., Luther, J., et al. (2013). Do menopausal status and use of hormone therapy affect antidepressant treatment response? Findings from the Sequenced Treatment Alternatives to Relieve Depression (STAR*D) study. J. Womens Health (Larchmt) 22, 121-131. doi: 10.1089/jwh.2012.3479

Kudo, K., Wati, H., Qiao, C., Arita, J., and Kanba, S. (2005). Age-related disturbance of memory and CREB phosphorylation in CA1 area of hippocampus of rats. Brain Res. 1054, 30-37. doi: 10.1016/j.brainres.2005. 06.045

Kupfer, D. J., Frank, E., and Phillips, M. L. (2012). Major depressive disorder: new clinical, neurobiological, and treatment perspectives. Lancet 379, 1045-1055. doi: 10.1016/S0140-6736(11)60602-8

Lenox, R., and Frazer, A. (2002). Mechanism of Action of Antidepressants and Mood Stabilizers: Neuropsychopharmacology. Philadelphia, PA: Lippincott Williams \& Wilkins, 1139-1163.

Lenze, E. J., Sheffrin, M., Driscoll, H. C., Mulsant, B. H., Pollock, B. G., Dew, M. A., et al. (2008). Incomplete response in late-life depression: getting to remission. Dialogues Clin. Neurosci. 10, 419-430.

Li, Y., Abdourahman, A., Tamm, J. A., Pehrson, A. L., Sanchez, C., and Gulinello, M. (2015). Reversal of age-associated cognitive deficits is accompanied by increased plasticity-related gene expression after chronic antidepressant administration in middle-aged mice. Pharmacol. Biochem. Behav. 135, 70-82. doi: 10.1016/j.pbb.2015.05.013

Lukes, A. (2008). Evolving issues in the clinical and managed care settings on the management of menopause following the women's health initiative. J. Manag. Care Pharm. 14, 7-13. 
Maartens, L. W., Knottnerus, J. A., and Pop, V. J. (2002). Menopausal transition and increased depressive symptomatology: a community based prospective study. Maturitas 42, 195-200. doi: 10.1016/S0378-5122(02)00038-5

Maki, P. M. (2012). Minireview: effects of different HT formulations on cognition. Endocrinology 153, 3564-3570. doi: 10.1210/en.2012-1175

Maki, P. M., Freeman, E. W., Greendale, G. A., Henderson, V. W., Newhouse, P. A., Schmidt, P. J., et al. (2010). Summary of the national institute on aging-sponsored conference on depressive symptoms and cognitive complaints in the menopausal transition. Menopause 17, 815-822. doi: 10.1097/gme. 0b013e3181d763d2

Mangoni, A. A., and Jackson, S. H. (2004). Age-related changes in pharmacokinetics and pharmacodynamics: basic principles and practical applications. Br. J. Clin. Pharmacol. 57, 6-14. doi: 10.1046/j.1365-2125.2003. 02007.x

Marcusson, J. O., Alafuzoff, I., Backstrom, I. T., Ericson, E., Gottfries, C. G., and Winblad, B. (1987). 5-Hydroxytryptamine-sensitive [3H]imipramine binding of protein nature in the human brain. II. Effect of normal aging and dementia disorders. Brain Res. 425, 137-145. doi: 10.1016/0006-8993(87)90492-6

Matt, D. W., Lee, J., Sarver, P. L., Judd, H. L., and Lu, J. K. (1986). Chronological changes in fertility, fecundity and steroid hormone secretion during consecutive pregnancies in aging rats. Biol. Reprod. 34, 478-487. doi: 10.1095/biolreprod34. 3.478

McEwen, B. S., and Alves, S. E. (1999). Estrogen actions in the central nervous system. Endocr. Rev. 20, 279-307. doi: 10.1210/edrv.20.3.0365

Meltzer, C. C., Kondziolka, D., Villemagne, V. L., Wechsler, L., Goldstein, S., Thulborn, K. R., et al. (2001). Serial [18F] fluorodeoxyglucose positron emission tomography after human neuronal implantation for stroke. Neurosurgery 49, 586-591. doi: 10.1097/00006123-200109000-00011 discussion 591-582,

Meltzer, C. C., Smith, G., Price, J. C., Reynolds, C. F. III, Mathis, C. A., Greer, P., et al. (1998). Reduced binding of [18F]altanserin to serotonin type 2 A receptors in aging: persistence of effect after partial volume correction. Brain Res. 813, 167-171. doi: 10.1016/S0006-8993(98)00909-3

Morrison, M. F., Kallan, M. J., Ten Have, T., Katz, I., Tweedy, K., and Battistini, M. (2004). Lack of efficacy of estradiol for depression in postmenopausal women: a randomized, controlled trial. Biol. Psychiatry 55, 406-412. doi: 10.1016/j. biopsych.2003.08.011

Nelson, J. C., Delucchi, K., and Schneider, L. S. (2008). Efficacy of second generation antidepressants in late-life depression: a meta-analysis of the evidence. Am. J. Geriatr. Psychiatry 16, 558-567. doi: 10.1097/JGP. ob013e3181693288

Owen, F., Chambers, D. R., Cooper, S. J., Crow, T. J., Johnson, J. A., Lofthouse, R., et al. (1986). Serotonergic mechanisms in brains of suicide victims. Brain Res. 362, 185-188. doi: 10.1016/0006-8993(86)91415-0

Pae, C. U., Mandelli, L., Kim, T. S., Han, C., Masand, P. S., Marks, D. M., et al. (2009). Effectiveness of antidepressant treatments in pre-menopausal versus post-menopausal women: a pilot study on differential effects of sex hormones on antidepressant effects. Biomed. Pharmacother. 63, 228-235. doi: 10.1016/j. biopha.2008.03.010

Parsey, R. V., Oquendo, M. A., Simpson, N. R., Ogden, R. T., Van Heertum, R., Arango, V., et al. (2002). Effects of sex, age, and aggressive traits in man on brain serotonin 5-HT1A receptor binding potential measured by PET using [C-11]WAY-100635. Brain Res. 954, 173-182. doi: 10.1016/S0006-8993(02) 03243-2

Paxinos, G., and Watson, C. (1986). The Rat Brain in Stereotaxic Coordinates, 6th Edn. New York, NY: Academic.

Polter, A. M., and Li, X. (2011). Glycogen synthase kinase-3 is an intermediate modulator of serotonin neurotransmission. Front. Mol. Neurosci. 4:31. doi: 10.3389/fnmol.2011.00031

Prior, J. C. (1998). Perimenopause: the complex endocrinology of the menopausal transition. Endocr. Rev. 19, 397-428. doi: 10.1210/edrv.19.4.0341

Recamier-Carballo, S., Estrada-Camarena, E., Reyes, R., and Fernandez-Guasti, A. (2012). Synergistic effect of estradiol and fluoxetine in young adult and middleaged female rats in two models of experimental depression. Behav. Brain Res. 233, 351-358. doi: 10.1016/j.bbr.2012.05.034

Resnick, S. M., and Henderson, V. W. (2002). Hormone therapy and risk of Alzheimer disease: a critical time. JAMA 288, 2170-2172. doi: 10.1001/jama. 288.17.2170
Rocca, W. A., Grossardt, B. R., and Shuster, L. T. (2011). Oophorectomy, menopause, estrogen treatment, and cognitive aging: clinical evidence for a window of opportunity. Brain Res. 1379, 188-198. doi: 10.1016/j.brainres.2010. 10.031

Rodriguez, J. J., Noristani, H. N., and Verkhratsky, A. (2012). The serotonergic system in ageing and Alzheimer's disease. Prog. Neurobiol. 99, 15-41. doi: 10. 1016/j.pneurobio.2012.06.010

Romano-Torres, M., and Fernandez-Guasti, A. (2010). Estradiol valerate elicits antidepressant-like effects in middle-aged female rats under chronic mild stress. Behav. Pharmacol. 21, 104-111. doi: 10.1097/FBP.0b013e328337bdfc

Rossouw, J. E., Anderson, G. L., Prentice, R. L., LaCroix, A. Z., Kooperberg, C., Stefanick, M. L., et al. (2002). Risks and benefits of estrogen plus progestin in healthy postmenopausal women: principal results From the Women's Health Initiative randomized controlled trial. JAMA 288, 321-333. doi: 10.1001/jama. 288.3.321

Salzman, C., Wong, E., and Wright, B. C. (2002). Drug and ECT treatment of depression in the elderly, 1996-2001: a literature review. Biol. Psychiatry 52, 265-284. doi: 10.1016/S0006-3223(02)01337-9

Schloss, P., and Williams, D. C. (1998). The serotonin transporter: a primary target for antidepressant drugs. J. Psychopharmacol. 12, 115-121. doi: 10.1177/ 026988119801200201

Severson, J. A., Marcusson, J. O., Osterburg, H. H., Finch, C. E., and Winblad, B. (1985). Elevated density of $[3 \mathrm{H}]$ imipramine binding in aged human brain. J. Neurochem. 45, 1382-1389. doi: 10.1111/j.1471-4159.1985.tb07203.x

Sheffrin, M., Driscoll, H. C., Lenze, E. J., Mulsant, B. H., Pollock, B. G., Miller, M. D., et al. (2009). Pilot study of augmentation with aripiprazole for incomplete response in late-life depression: getting to remission. J. Clin. Psychiatry 70, 208-213. doi: 10.4088/JCP.07m03805

Shughrue, P. J., and Merchenthaler, I. (2000). Estrogen is more than just a "sex hormone": novel sites for estrogen action in the hippocampus and cerebral cortex. Front. Neuroendocrinol. 21:95-101. doi: 10.1006/frne.1999.0190

Soares, C. N. (2013). Depression in peri- and postmenopausal women: prevalence, pathophysiology and pharmacological management. Drugs Aging 30, 677-685. doi: 10.1007/s40266-013-0100-1

Soares, C. N., Almeida, O. P., Joffe, H., and Cohen, L. S. (2001). Efficacy of estradiol for the treatment of depressive disorders in perimenopausal women: a doubleblind, randomized, placebo-controlled trial. Arch. Gen. Psychiatry 58, 529-534. doi: $10.1001 /$ archpsyc.58.6.529

Soares, C. N., and Frey, B. N. (2010). Is there a role for estrogen in treating depression during menopause? J. Psychiatry Neurosci. 35, E6-E7. doi: 10.1503/ jpn. 100128

Tauscher, J., Verhoeff, N. P., Christensen, B. K., Hussey, D., Meyer, J. H., Kecojevic, A., et al. (2001). Serotonin 5-HT1A receptor binding potential declines with age as measured by [11C]WAY-100635 and PET. Neuropsychopharmacology 24, 522-530. doi: 10.1016/S0893-133X(00)00227-X

Tedeschini, E., Levkovitz, Y., Iovieno, N., Ameral, V. E., Nelson, J. C., and Papakostas, G. I. (2011). Efficacy of antidepressants for late-life depression: a meta-analysis and meta-regression of placebo-controlled randomized trials. J. Clin. Psychiatry 72, 1660-1668. doi: 10.4088/JCP.10r06531

Turnheim, K. (2003). When drug therapy gets old: pharmacokinetics and pharmacodynamics in the elderly. Exp. Gerontol. 38, 843-853. doi: 10.1016/ S0531-5565(03)00133-5

Vega Rivera, N. M., Gallardo Tenorio, A., Fernandez-Guasti, A., and Estrada Camarena, E. (2016). The post-ovariectomy interval affects the antidepressantlike action of citalopram combined with ethynyl-estradiol in the forced swim test in middle aged rats. Pharmaceuticals (Basel) 9:E21. doi: 10.3390/ph9020021

Walf, A. A., Paris, J. J., and Frye, C. A. (2009). Chronic estradiol replacement to aged female rats reduces anxiety-like and depression-like behavior and enhances cognitive performance. Psychoneuroendocrinology 34, 909-916. doi: 10.1016/j.psyneuen.2009.01.004

Wang, J. M., Hou, X., Adeosun, S., Hill, R., Henry, S., Paul, I., et al. (2012). A dominant negative ERbeta splice variant determines the effectiveness of early or late estrogen therapy after ovariectomy in rats. PLoS ONE 7:e33493. doi: 10.1371/journal.pone.0033493

Weiser, M. J., Foradori, C. D., and Handa, R. J. (2008). Estrogen receptor beta in the brain: from form to function. Brain Res. Rev. 57, 309-320. doi: 10.1016/j. brainresrev.2007.05.013 
Wise, P. M., and Ratner, A. (1980). Effect of ovariectomy on plasma LH, FSH, estradiol, and progesterone and medial basal hypothalamic LHRH concentrations old and young rats. Neuroendocrinology 30, 15-19. doi: 10.1159/ 000122968

Xu, J., Rong, S., Xie, B., Sun, Z., Deng, Q., Wu, H., et al. (2010). Memory impairment in cognitively impaired aged rats associated with decreased hippocampal CREB phosphorylation: reversal by procyanidins extracted from the lotus seedpod. J. Gerontol. A Biol. Sci. Med. Sci. 65, 933-940. doi: 10.1093/ gerona/glq094

Yamaguchi, N., and Yuri, K. (2014). Estrogen-dependent changes in estrogen receptor-beta mRNA expression in middle-aged female rat brain. Brain Res. 1543, 49-57. doi: 10.1016/j.brainres.2013.11.010

Yamamoto, M., Suhara, T., Okubo, Y., Ichimiya, T., Sudo, Y., Inoue, M., et al. (2002). Age-related decline of serotonin transporters in living human brain of healthy males. Life Sci. 71, 751-757. doi: 10.1016/S0024-3205(02) 01745-9

Zhang, Q. G., Han, D., Wang, R. M., Dong, Y., Yang, F., Vadlamudi, R. K., et al. (2011). C terminus of Hsc70-interacting protein (CHIP)-mediated degradation of hippocampal estrogen receptor-alpha and the critical period hypothesis of estrogen neuroprotection. Proc. Natl. Acad. Sci. U.S.A. 108, E617-E624. doi: $10.1073 /$ pnas. 1104391108

Conflict of Interest Statement: Dr. Benmansour and Mr. Arroyo have no biomedical financial interests or potential conflicts of interest. Dr. Frazer has been on advisory boards for Cyberonics, Inc., H. Lundbeck A/S, and Takeda Pharmaceuticals America, Inc. and he has consulted and/or received research support for preclinical studies from Forest Research Institute, Eli Lilly and Company, Wyeth Pharmaceuticals, and H. Lundbeck A/S. No support for this study was received from any pharmaceutical company.

Copyright (c) 2016 Benmansour, Arroyo and Frazer. This is an open-access article distributed under the terms of the Creative Commons Attribution License (CC BY). The use, distribution or reproduction in other forums is permitted, provided the original author(s) or licensor are credited and that the original publication in this journal is cited, in accordance with accepted academic practice. No use, distribution or reproduction is permitted which does not comply with these terms. 